\title{
FLUORESCENCE INTENSITY CORRELATIONS: DETECTION AND ANALYSIS BY PHOTON COUNTING USING A CLIP-CORRELATOR
}

Apparatus for the studies of fluorescence intensity correlations is described. The diffusion constants of two dyes, Rhodamine 6G and Uranine in water, are measured. Values of the diffusion constants as well as the signal-to-noise ratio are found to be in agreement with those predicted by theoretical calculations.

\section{Introduction}

Concentration correlation studies can be treated and described as observing the average behavior of a thermodynamic system after a stochastic fluctuation away from equilibrium. According to the fluctuation-dissipation theorem $\left[{ }^{1}\right]$, this procedure is equivalent to observing relaxation of the system after a macroscopic perturbation. Since the basic work of D. Magde, E. L. Elson and W. W. Webb $\left[{ }^{2-4}\right]$ the correlation measurements of concentration, monitored by intensity of fluorescence emission (so-called fluorescence correlation (FC) spectroscopy) have passed an intensive development, basically, by these authors themselves and their co-workers $\left[{ }^{5-8}\right]$ for studying translational diffusion in a large variety of objects, especially in membranes [ $\left.{ }^{9-11}\right]$. To obtain information about chemical kinetics $\left[{ }^{3,12,13}\right]$ and rotational diffusion $\left[{ }^{14-16}\right]$, also available by this method, relatively less experimental work has been done.

We shall not treat here the advantages of photon counting relative to photocurrent measurements in determining the light intensity fluctuations. The most recent $\mathrm{FC}$ spectrometers $\left[{ }^{8,16}\right]$ include photon counting and fast data processing on minicomputers. In the case of translational diffusion studies the channel width almost always exceeds $1 \mathrm{msec}$ and the software computer is, perhaps, sufficiently fast for real-time data processing $\left[{ }^{8}\right]$. However, in the case of chemical kinetics and rotational diffusion studies, where the time windows much less than $1 \mathrm{msec}$ are often needed, we expect the software processing to be too time consuming.

Since the paper by E. Jakeman and E. R. Pike $\left[{ }^{17}\right]$ about the fluctuation spectroscopy of scattered light intensity (photon correlation spectroscopy), the hardware clip-correlators are widely used. Their scheme of processing allows a quick real-time processing with the minimum time window usually less than $10^{-7} \mathrm{sec}$. We consider it as natural to introduce the clip-correlator in FC spectroscopy, too. It has been shown that in FC studies, the use of the clip-correlator does not distort the shape of the signal (or more precisely, the distortion is linear) and reduces the 


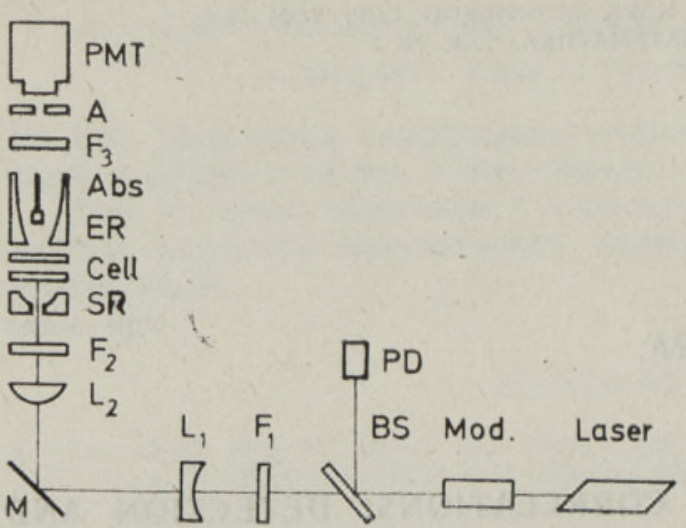

Fig. 1. Schematic diagram of the optical part of an FC spectrometer. $F_{1}$, attenuator; $F_{2}, \quad F_{3}$, colored filters; $L_{1}, L_{2}$, lenses; $B S$, beamsplitter; $M$, mirror; $S R$, spherical reflector; $E R$, elliptical reflector; $A b s$, absorber; $A$, aperture; $P D$, photodiode; PMT, photomultiplier; Mod, modulator.

signal-to-noise ratio only about $(\pi / 2)^{1 / 2} \cong 1.25$ times at the usual experimental conditions $\left[{ }^{18}\right]$.

Below we shall describe our FC spectrometer and the results of some preliminary experiments on translational diffusion. We shall also discuss the main criteria in the design of FC spectrometers.

\section{Experimental methods}

Optics. A schematic diagram of the optical part of our apparatus is shown in Fig. 1.

The beam from an argon laser at $457.9 \mathrm{~nm}$ is stabilized and, after passing a neutral density filter, functioning as attenuator, is focused through a long focus dispersing lens $L_{1}$, vertical mirror $M$ and a short focus achromatic lens $L_{2}(O M-11(3.7 \times 0.11))$ on the sample cell. The effective radius of the light spot is estimated to be $w=1.6 \mu \mathrm{m}$, whereas the power of the laser is attenuated to about $1.5 \mathrm{~mW}$.

The cell is made of two fused silica windows, with a sample layer between the windows. The thickness of the layer is fixed by thin came! hairs placed between the windows and is about $20 \mu \mathrm{m}$.

The blue filter $F_{2}$ is used to avoid fluorescence light, emitted from the objective lens $L_{2}$. The fluorescence of sample molecules, excited by the iocused beam, is collected by spherical and elliptical reflectors $S R$ and $E R$, passed through a liquid filter $F_{3}$ and detected by the EMI $9558 \mathrm{QB}$ photomultiplier (with S-20 cathode) in the photon counting mode.

The straightforward laser beam is absorbed by absorber $A b s$. The liquid filter $F_{3}$, made of a $33 \%$ solution of $\mathrm{Na}_{2} \mathrm{CrO}_{4}$ contained in a cell with fused silica windows, cuts off the scattered laser light.

The aperture $A$ in front of the photomultiplier tube serves for cutting off the fluorescence emission originating from other parts of the system except the cell itself.

The objective, filters, reflectors and cell are mounted in a massive copper mount to prevent temperature fluctuations caused by the room temperature drift.

The whole optical system is mounted on a rigid steel table. Special pneumatic supports were found to be unnecessary.

Electronics. The electronics consists of a stabilizing system for compensation of the laser intensity fluctuations, a photon counting system, a digital correlator and output devices.

The laser intensity stabilizing system is built around a standard electron-optical Pockels modulator (type МЛ-4), driven by the photodiode current in a negative feedback system (see Fig. 1). The stabilizer, 
Fig. 2. The normalized correlation function, $G_{C}$, for translational diffusion of: (1) Rhodamine 6G (at $2 \times 10^{-8} \mathrm{M}$ in water) and (2) Uranine (at $3 \times 10^{-8}$ $M$ in water) at room temperature.

operating from 0 to $100 \mathrm{kHz}$, reduces the peak-to-peak value of the most prominent fluctuations of laser intensity, occurring at 50,100 and $300 \mathrm{~Hz}$, to $\leqslant 0.3 \%$.

Pulses from the EMI 9558QB photomultiplier are amplified and standardized by discriminator. The level of discrimination is $1 \mathrm{mV}$. The pulse pair resolution of discrimination is $25 \mathrm{nsec}$, whereas that of the photo-

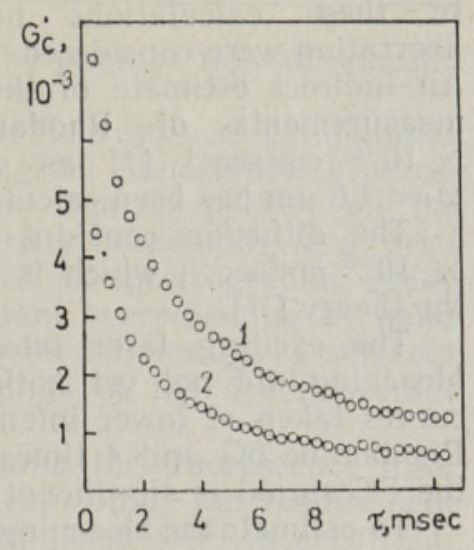
multiplier is 70 nsec.

The autocorrelation function of the sequence of pulses of $10 \mathrm{nsec}$ minimum width is calculated using a 32 -channel clip-correlator $\left[{ }^{19}\right]$. This correlator makes it possible to obtain auto- and cross-correlation functions of sequences of digital pulses up to $50 \mathrm{MHz}$ on line with the experimental data storage, with 50 nsec dead time per channel; it has a wide range of clipping levels (from 0 to $2^{19}-1$ ) and channel widths (from 100 nsec to $2^{23} \times 100$ nsec $=0.84 \mathrm{sec}$ ). This makes it possible to obtain correlation functions with characteristic times $\tau=10^{-6} \mathrm{sec}$ to $10 \mathrm{sec}$.

\section{Results}

Fluorescence intensity autocorrelation functions for the translational diffusion of some dyes in water are shown in Fig. 2. The ordinate represents the normalized correlation function, the abscissa - the time delay $\tau$. The first curve is the autocorrelation function of Rhodamine $6 \mathrm{G}$, the second - that of Uranine both at $20^{\circ} \mathrm{C}$.

The total run time was $1 / 2$ and $1 \mathrm{~h}$, and the mean photon counting rate $0.78 \times 10^{6}$ and $0.35 \times 10^{6} \mathrm{cps}$, respectively.

The curve fitting was carried out on an EMG-666 computer. According to $\left[{ }^{4}\right]$, the approximation curve has the form

$$
g(\tau)=A /\left(1+\tau / \tau_{D}\right)+B,
$$

where $\tau_{D}$ is the correlation time, $A$ - the signal related to zero delay, $B$ - the incorrelated part of the correlator channel content. An algorithm of the linearized least squares method was used. The linearization was held in approximation similarly to that used in the case of exponential functions $\left[{ }^{20}\right]$.

Curve fittings gave the following correlation time estimates: $\tau_{D}=1.82 \mathrm{msec}$ for Rhodamine $6 \mathrm{G}$ and $\tau_{D}=1.37 \mathrm{msec}$ for Uranine. These results have proven to be reproducible over long periods of time within $3 \%$ accuracy.

Although there is a number of methods to determine the spot size of the focused laser beam, we have made only the simplest calculation according to $\left[{ }^{21}\right]$. Dispersed beam intensity at the aperture plane falls about 5 times from the center to the edge of the aperture. Knowing the aperture number $(0.11)$, we have calculated the spot radius (intensity, fallen $e^{2}$ times) at the focus to be $w_{0}=1.14 \mu \mathrm{m}$ and at a distance of $10 \mu \mathrm{m}$ (half of the thickness of the cell) $w(10 \mu \mathrm{m})=1.71 \mu \mathrm{m}$. 
In these calculations neither aperture distortions nor spherical aberration were considered.

An indirect estimate of the spot radius is the result of our diffusion measurements of Rhodamine 6G. Taking the value $D=3.5 \times$ $\times 10^{-6} \mathrm{~cm}^{2} \mathrm{sec}^{-1}\left[{ }^{4}\right]$ as granted, the effective radius of the spot $w=1.6 \mu \mathrm{m}$ has been calculated.

The diffusion constant of Uranine was calculated to be $4.6 \times$ $\times 10^{-6} \mathrm{~cm}^{2} \mathrm{sec}^{-1}$, which is in a good agreement with that predicted by the theory $\left[{ }^{22}\right]$.

The exciting laser intensity was held on the level, where photobleaching did not yet noticeably distort the curve, compared with the curves taken at lower intensities, and was about $1.5 \mathrm{~mW}$ in the case of Rhodamine $6 \mathrm{G}$ and 4 times less in the case of Uranine. A distortion of the FC signal is significant at 4 times higher laser intensities.

To estimate the bleaching efficiency, we have measured the fluorescence intensity decay curves after starting the continuous illumination. Such an experiment is close to the photobleaching recovery measurements $\left[{ }^{23}, 24,8\right]$ and, in principle, allows one to estimate both the diffusion time $\tau_{D}$ and its ratio to the bleaching time, $\tau_{D} / \tau_{B}$, the latter, however, with a much better accuracy (note also that $\tau_{D} / \tau_{B}$ does not depend on the beam radius at given integral illuminating intensity). We found the diffusion rate to be about 40 times higher than the bleaching rate at laser intensities used in the FC studies described above. So the distortion of the signal caused by photobleaching is insignificant.

We have also verified the accordance of theoretical and experimental singal-to-noise ratios. In theoretical calculations the following formula for signal-to-noise ratio is used $\left[{ }^{18,5}\right]$ :

$$
(S / N)^{0}=(2 / \pi)^{1 / 2 i \beta} \sqrt{T \theta},
$$

where $i$ is the mean photon counting intensity, $\beta$ the reciprocal effective mean number of dye molecules inside the illuminated volume, $T$ channel width of the clip-correlator, and $\theta-$ the total run time. It describes the amplitude of the signal (reduced to zero delay), related to the root mean square deviation of the content of a correlator channel.

The experimental values of the signal-to-noise ratio were found to be in agreement with those predicted by the formula (2) within $30 \%$ accuracy, which is satisfactory, taking into account the inaccuracies in estimating of a number of primary variables in our experiment.

\section{Discussion}

Our system is designed for correlation analysis of fluorescence intensity fluctuations. Though the preliminary experiments are carried out on translational diffusion of dyes, our aim is to use this system to study rotational diffusion and the kinetics of chemical reactions. Nevertheless, we could determine some advantages and limits of our system, as compared with some other competing ones.

As it was pointed out by D. E. Koppel et al. $\left[{ }^{8}\right]$, among a number of difficulties, photobleaching seems to be the most serious one, hindering one to raise the laser intensity and therefore to improve the signal-tonoise ratio. At laser intensities useful for FC signal recovery, the natural diffusion of large molecules is not fast enough to refresh the fluorescent solution inside the laser beam, especially if fast processes (chemical 
kinetics or rotational diffusion) are studied. The laminar flow of solution through the cell $\left[{ }^{7}\right]$ solves the problem.

The other difficulties are caused by parasitic fluorescence. To minimize it thorough cleaning of optical surfaces is of great importance. Fluorescence of fused silica surfaces exposed to air, depends greatly on the way of cleaning. We realized that, from the variety of methods (e. g. brief heating in a flame, cleaning with solvents such as spectrographic grade acetone, polishing, etc.) some minutes of brilliant overpolishing by hand gives the best results. Though a brief heating in a flame gives surfaces with very little fluorescence, subsequent «gluing» of the dye molecules to the surfaces would be too efficient.

There are two important criteria in designing the fluorescence light collecting optical system of the FC spectrometer: first, the requirement of high collecting efficiency (note: the signal-to-noise ratio in a correlation experiment is proportional to the mean counting rate, not to the square of it, as in usual counting systems) and second, the requirement to cut off geometrically the background fluorescence, originating from optical materials and surfaces except the sample itself.

If large aperture reflection optics is used (collection near $4 \pi$ is possible), the large aberrations do not allow exact diaphragming of the background fluorescence and special care should be taken to minimize the latter. The special cleaning of the cell windows before every experiment is quite uncomfortable and time consuming. This problem is well solved in the case when the system does not consist of quartz-air surfaces exposed to the laser beam near the fluorescing sample, as the quartzwater surfaces do not show so strong a fluorescence.

On the contrary, microscope optics collects emission over the space angle of only about $0.15 \times 4 \pi$ (if the aperture number is about 1.0 ), but diaphragming is simple. Losses in the collecting efficiency can partially be compensated by the raised photon detection efficiency, achievable in the case of a nearly parallel light beam by multiple internal reflection in the cathode window of the photomultiplier tube.

The optical system, described above, has disadvantages of both types. However, the collection efficiency could be raised by replacing one of the cell windows by a convex lens.

\section{REFERENCES}

1. C alle n, H. B., Welt on, T. A., Phys. Rev., 83, № 1, 34-46 (1951).

2. Magd e, D., E 1 s o n, E. L., W e b b, W. W., Phys. Rev. Lett., 29, № 11, 705-708 (1972).

3. E 1 s o n, E. L., M a g d e, D., Biopolymers, 13, № 1, 1-27 (1974)

4. Ma g d e, D., E ls o n, E. L., W e b b, W. W., Biopolymers, 13, № 1, 29-61 (1974),

5. Ko p pel, D. E., Phys. Rev., A10, № 6, 1938-1945 (1974).

6. E I s o n, E. L., W e b b, W. W., Ann. Rev. Biophys. Bioeng., 4, 311-334 (1975).

7. M a g de, D., W e b b, W. W., E I s o n, E. L., Biopolymers, 17, № 3, 361-376 (1978).

8. Koppel, D. E., Axelrod; D., S chles s ing er, J., Els on, E. L., Webb,W. W., Biophys, J., 16, № 12, 1315-1329 (1976).

9. We b b, W. W., Quart. Rev. Biophys., 9, 49-68 (1976).

10. Schlessinger, J., Koppel, D. E., Axelrod, D., J a cobson, K., Webb, W. W., E I s o n, E. L., Proc. Nat. Acad. Sci. USA, 73, № 7, 2409-2413 (1976).

11. F a he y, P. E., Koppel, D. E., B a rak, L. S., Wolf, D. E., Elson, E. L., W e b b, W. W., Science, 195, 305-306 (1977).

12. M a g d e, D., Quart. Rev. Biophys., 9, № 1, 35-48 (1976).

13. M a g d e, D., In: Chemical Relaxation in Molecular Biology, Springer-Verlag, Berlin, 1977, p. $43-244$.

14. Ehrenberg, M., Rig ler, R., Chem. Phys., 4, № 3, 390-401 (1974).

15. A r a g o n, S. R., Pe cora, R., J. Chem. Phys., 64, № 4, 1791-1803 (1975). 
16. Ehren berg, M., Rig le r, R., Quart. Rev. Biophys., 9, № 1, 69-81 (1976).

17. J a kem a n, E., Pike, E. R., J. Phys., A2, № 2, 411-412 (1969).

18. Kask, P., Kändler, T., ENSV TÁ Toim., Füüs. Matem., 27, № 1, 73-78 (1978).

19. S irk, A., Kask, P., Kändler, T., Karu, T., Puskar, J., Lippmaa, E., ENSV TA Toim., Füüs. Matem., 28, № 3, 227-232 (1979).

20. H i g b i e, J., Nucl. Instrum. Meth., 105, № 3, 279-282 (1972).

21. I n n e s, D. J., B l o o m, A. L., Spectra-Phys. Laser Techn. Bull., № 5, 1966.

22. Long s w orth, L. G., J. Amer. Chem. Soc., 74, № 19, 4155-4159 (1952).

23. Peters, R., Peters, J., Tows, K., Bähr, W., Biochim, et biophys. acta, 367, № 3, 282-286 (1974).

24. Schlessinger, J., Axelrod, D., Koppel, D. E., Webb, W. W., E1son, E. L., Science, 195, 307-309 (1977).

Academy of Sciences of the Estonian SSR, Institute of Cybernetics

Received March. 30, 1979

P. KASK, T. KANDLER, A. SIRK,

T. KARU, E. LIPPMAA

FLUORESTSENTSI INTENSIIVSUSE KORRELATSIOONID: DETEKTEERIMINE JA ANALUUS FOOTONITE LOENDAMISE MEETODIL CLIP-KORRELAATORIT KASUTADES

On kirjeldatud fluorestsentsi intensiivsuse korrelatsioonmõõtmise katseseadet ning mõōdetud kahe värvaine - rodamiin $6 \mathrm{G}$ ja uraniini - difusioonikonstandid vesilahustes. Nii difusioonikonstandid kui ka signaali-müra suhe on kooskõlas teoreetiliste suurustega.

П. КАСК, Т. КЯНДЛЕР, А. СНРК,

T. КАРУ, Э. ЛИППМАА

\section{КОРРЕЛЯЦИИ ИНТЕНСИВНОСТИ ФЛУОРЕСЦЕНЦИИ: ДЕТЕКТИРОВАНИЕ \\ И АНАЛИЗ МЕТОДОМ СЧЕТА ФОТОНОВ С ИСПОЛЬЗОВАНИЕМ КОРРЕЛЯТОРА С ПРИВЯЗКОИ В ОДНОМ КАНАЛЕ}

Описывается установка для измерения корреляции интенсивности флуоресценции. Измерены константы диффузии двух красителей родамина 6Ж и уранина в водных растворах. Как значения констант диффузии, так и отношение сигнала к шуму соответствуют результатам теории. 